\title{
reviews
}

columns

\section{Reading about self-help books on depression}

Self-help resources for depression are widely available in bookshops and via the internet. They are increasingly being recommended for use by healthcare practitioners as part of a stepped care treatment package (Bower \& Gilbody, 2005). Such materials provide key information and key skills to help readers tackle mild-to-moderate depression (National Institute for Clinical Excellence, 2004). The recent review of self-help by the National Institute for Mental Health in England confirmed that it is cognitivebehavioural therapy (CBT) self-help that has an evidence base rather than self-help per se (Lewis et al, 2003).

Evidence for the effectiveness of CBT self-help materials varies in quality. Some reviews have been very enthusiastic in recommending the effectiveness of written CBT self-help materials (so-called bibliotherapy). Other more recent and high-quality reviews have been more measured. Although there are a number of self-help books for the treatment of depression there is little direct evidence for the effectiveness of most available books (Anderson et al, 2005).

\section{Books and book prescription schemes}

The majority of specialists who treat patients with depression using CBT utilise written self-help materials (Keeley et al, 2002). These are used in a variety of settings to supplement individual or group therapy, for use by those on waiting lists and within book prescription schemes in primary care. It may be that practitioner support for the use of such books is essential and to date no controlled studies of book schemes have been published.

A growing number of book prescription schemes have developed around the UK (Farrand, 2005) and an example is shown in Table 1. A large range of self-help books are included on 'recommended' lists, which cover a range of mental health disorders.

The average UK reading age has been quoted as being around 9 years (Alderson, 1994), and it is clear that a proportion of patients will have problems following the content of some or all of the publications. Some books allow photocopying of either part or all of their content by professionals during their treatment of patients (e.g. Greenberger \& Padesky, 1995; Williams, 2001).

\section{Leaflets}

Sometimes patients prefer or require information in a shorter format. Locally

Table 1. Self-help books for depression available on the Peninsula book prescription scheme (Farrand, 2005)

Book

Comments

The Feeling Good Handbook (Burns, 1999) American book. Long but comprehensive. Evaluated in several RCTs.

Overcoming Depression (Gilbert, 2000) UK book. Many case examples, psychoevolutionary stance. Praised for its compassionate approach.

Mind Over Mood (Greenberger

\& Padesky, 1995)

American self-help manual containing worksheets and homework tasks using the traditional CBT language.

Overcoming Depression: A Five Areas UK self-help manual containing workbooks and worksheets. Avoids much of the traditional CBT language. Reading age 9-12 for most of the content.

$\mathrm{RCT}$, randomised controlled trials; CBT, cognitive-behavioural therapy.

Table 2. Sources of commonly used leaflets on depression that are available online

Source

BABCP

(http://www.babcp.com)

Depression Alliance

(http://www.depressionalliance.org/

docs/what_we_offer/publications.html)

MIND

(http://www.mind.org.uk/Information/ Factsheets)

Northumberland CBT materials (http://www.nnt.nhs.uk/mh/ content.asp?PageName=selfhelp)

Royal College of Psychiatrists (http://www.rcpsych.ac.uk/info/ dep.htm )

Steps

(http://www.glasgowsteps.com / help.html)
Comment

The lead body for CBT in the UK provides a range of free leaflets that are frequently updated.

A range of free leaflets addressing depression and sex, St John's Wort depression at Christmas, treatments, etc

A wide range of free-to-read leaflets which can be read but not printed also available for purchase.

Excellent series of self-help leaflets addressing a wide range of issues such as overcoming anger, guilt, shame, etc., as well as low mood, etc.

Many leaflets addressing varying aspects of depression - e.g. depression in men, postnatal depression, etc.

Wide range of self-help materials produced by an innovator in the area of self-help delivery. 
produced leaflets are available in many clinical units and leaflets with a wider circulation are freely available online (Table 2)

\section{Other websites}

A range of self-help websites and leaflets are increasingly available via the internet (Fig. 1).

Few studies have examined the effectiveness of psychoeducational websites in helping people with depression however, some studies have found them to be as effective as online CBT (Christensen et al, 2004). Most sites at present provide simple information about depression. Two sites in particular offer information and life skills training for people facing low mood and depresion: Mood Gym (http:// moodgym.anu.edu.au/) and Living Life to the Full (www.livinglifetothefull.com).

\section{Conclusion}

It is clear that there is an apparently insatiable desire of users and patients to obtain information about depression. This is reflected by the increasing numbers of books and websites that are available. Practitioners are also increasingly offering information leaflets and such approaches are being formalised within clinical services. Such developments may have run ahead of the evidence base and more research in practice is required.

\section{Declaration of interest}

C.W. is author of one of the Overcoming Depression and Living Life to the Full websites.

\section{References}

ALDERSON, P. (1994) As plain as can be. Health Service Journal, 106, 28-29.

ANDERSON, L., LEWIS, G., ARAYA, R., et al (2005) Self-help books for depression: how can practitioners and patients make the right choice? British Journal of General Practice, 55, 307-392.

BOWER, P. \& GILBODY, S. (2005) Stepped care in psychological therapies: access, effectiveness and efficiency: narrative literature review. British Journa of Psychiatry, 186, 11-17.
BURNS, D. (1999) The Feeling Good Handbook. London: Penguin Books.

CHRISTENSEN, H., GRIFFITHS, K. M. \& JORM, A. F. (2004) Delivering interventions for depression by using the internet: randomized controlled trial. BM 328, 265 .

FARRAND, P. (2005) Development of a supported self-help book prescription scheme in primary care. Primary Care Mental Health, 3, 61-66.

GILBERT, P. (2000) Overcoming Depression. London: Constable \& Robinson.

GREENBERGER, D. \& PADESKY, C. A. (1995) Mind over Mood. NewYork: Guilford Press.

KEELEY, H. WILLIAMS, C. J., \& SHAPIRO, D. (2002) A United Kingdom survey of accredited cognitive behaviour therapists' attitudes towards and use of structured self-help materials. Behavioural and Cognitive Psychotherapy, 30, 191-201.

LEWIS, G., ANDERSON, L., ARAYA, R., et al (2003) Self-Help Interventions for Mental Health Problems.http://www.dh.gov.uk/assetRoot/04/ 12/57/94/04125794.pdf

NATIONAL INSTITUTE FOR CLINICAL EXCELLENCE (2004) Depression: The Management of Depression in Primary and Secondary Care. London: NICE.

WILLIAMS, C. J. (2001) Overcoming Depression: A FiveAreas Approach. London: Arnold.

Graeme Whitfield Consultant Psychiatrist in Cognitive-Behavioural Therapy, Leicestershire Partnership NHS Trust, * Chris Williams Senior Lecturer in Psychiatry, University of Glasgow, e-mail: chris.williams@clinmed.gla.ac.uk

\section{Mental Health Law - A Practical Guide}

Basant K. Puri, Robert A. Brown Heather J. McKee, et al. London: Hodder Arnold, 2005, £19.99 pp. 254. ISBN: 0-340-88503-3

What a frustrating book. I started the review by thinking of a few examples of questions which are commonly asked on training courses. What is meant by 'mental illness'? Who can be a nominated deputy or send patients on leave? What 'counts' as medication for mental disorder? What is my role in a mental health review tribunal and what makes a good report? I looked for guidance. Unfortunately none of these topics is mentioned let alone answered. This was my first frustration. The second is that much of the book has little to do with mental health law. There are chapters on drug administration errors, clinical trials, European law in relation to medical qualifications, contractual responsibilities and liability for service provision, and the responsibilities of the Secretary of State under the NHS Act. No doubt all useful material but not what I expected from a book with this title.

Many relevant topics are covered but I was frustrated by the priorities. Chapters on the Children Act, mentally disordered offenders and risk assessment were both interesting and helpful, although I doubt that those who require a very detailed description of Hare's Psychopathy Checklist also need guidance on the categories of mental disorder. Although pleased to see a section on race and culture, why have a table on 'racist incidents in parts of England' rather than one on ethnicity and rates of detention under the Mental Health Act 1983? I was irritated by six pages on the procedures for transferring detained patients around the UK and another six wasted on a transcript of General Medical Council guidance on confidentiality.

A further frustration is the lack of accuracy. The assessment of capacity in relation to medical treatment is discussed three times but the guidance differs on each occasion. Then there are the factual errors. It states that the responsible medical officer can override a request for discharge by the nearest relative by certifying that 'the patient needs to be in hospital' and the list under the heading 'the patient may be discharged by any of the following' omits the mental health review tribunal (although that is mentioned later). A Form 38 completed, as suggested, would not comply with the Code of Practice.

Do not misunderstand me. This book contains a lot of valuable information. I am confident most readers would find much of interest. Another reviewer, and many colleagues, with different expectations, might like the unusual and varied range of material. It just was not what I expected from the title.

Tony Zigmond Consultant Psychiatrist, Newsam Centre, Seacroft Hospital, York Road, Leeds LS14 6WB 